\title{
Online Teaching: Myths, Misconceptions, ANd Cold HaRd Realities
}

\author{
Carol M. Fischer and Michael f. Fischer
}

Carol M. Fischer (cfischer@sbu.edu) and Michael J. Fischer (mfischer@sbu.edu) are both Professors of Accounting at St. Bonaventure University, 3261 W. State Street, St. Bonaventure, NY 14778. Correspondence concerning this paper should be directed to Carol M. Fischer.

\begin{abstract}
There are many interesting strategic and policy issues surrounding the adoption of online programs. However, the heart of any online program - and the key to its success - is with the faculty who develop and teach online courses. This paper focuses on the faculty, addressing common myths and misconceptions about online instruction, and offering a case study on developing online teaching skills.

The two authors developed and taught two different online accounting courses in a fully-online MBA program that launched in fall 2016. We share our experiences developing and delivering the courses (both taught in spring 2017). After addressing myths and misconceptions, we provide concrete suggestions for making the transition from face-to-face to online teaching. Based on our
\end{abstract}


experiences, we share lessons learned - what worked, what didn't work, and how we are moving toward continuous improvement of both the course and the instructional approach.

Keywords: online teaching skills, online education, faculty perceptions of online teaching

DOI: http://dx.doi.org/10.15239/j.brcadvje.2018.03.01.ja03

\section{INTRODUCTION}

The number of students taking online classes and the number of institutions offering online courses has grown significantly over the past decade. From 2002 to 2014, the number of students taking at least one online course grew by $262 \%$ (Poulin \& Straut, 2016), far outpacing overall enrollment growth in colleges and universities, which increased $32 \%$ over a somewhat longer timeframe from 2000 to 2014 (National Center for Education Statistics, 2016). In more recent years, the growth in online enrollments has moderated considerably, with online enrollments in at least one course growing by 7\% from 2012 to 2014; however, enrollments in on-ground programs declined by $2 \%$ during this same period (Poulin \& Straut, 2016, pgs 3-4). A natural response is for many traditional universities to consider offering online programs. Despite varying degrees of faculty and administrative resistance, the movement toward online education is clearly more than a passing trend. Thus, there has been a shift from asking whether institutions should offer online programs to asking how and to what extent online education should be offered by traditional on-ground universities.

There are many interesting strategic and policy issues surrounding the adoption of online programs. However, the heart of any online program - and the key to its success - is with the faculty who develop and teach the online courses. This paper focuses on the faculty, addressing common myths and misconceptions about online instruction, and offering a case study on developing online teaching skills. 
The remainder of the paper is organized as follows: In the first section, we discuss common myths and misconceptions about online instruction. Next, we briefly describe the online program in which we taught, including some of the policies that were adopted to incentivize faculty to teach online and the support that was offered to instructors. In the third section, we provide concrete suggestions for making the transition from faceto-face to online teaching. Based on our experiences, we share lessons learned - what worked, what didn't work, and how we are moving toward continuous improvement of both the courses and the instructional approach. Finally, we provide a summary and concluding comments with respect to the overall experience.

\section{Myths AND Misconce PTIONS}

"A continuing failure of online education has been the inability to convince its most important audience - higher education faculty members - of its worth (Allen and Seaman, 2016, pg. 26)." One study examined faculty perceptions of online accounting coursework by asking faculty members how willing they believe their institution should be in accepting online accounting courses for transfer credit (Grossman and Johnson, 2015). Although respondents were generally willing to grant credit for online courses at the introductory level from a traditional AACSBaccredited institution, this willingness decreased significantly when the coursework was completed in an online only environment. Further, participants were not confident that online courses developed technical or soft skills, expressed concerns about academic integrity in the online environment, and questioned the rigor of online courses (Grossman and Johnson, 2015, pg. 103). Faculty resistance to online education may stem from misconceptions regarding the quality of online courses and the ability to achieve learning outcomes comparable to those produced by face-to-face instruction.

In its web-based resources for online instructors, Xavier University addresses several misconceptions regarding online instruction (Xavier 


\section{BRC Journal of Advances in Education Vol. 3, No. 1}

University). Perhaps the most serious concern is that students won't learn as much in an online course. One recent research study administered to over 350 online students reported that almost $40 \%$ agreed with the statement "I feel I learn as much in my online class as I have in my face-to-face class," while $29 \%$ were neutral and $31 \%$ of the respondents disagreed. Interestingly, however, the same survey reported that only $20 \%$ of students felt they learned more in online courses, while $48 \%$ indicated that they learn more in face-to-face classes and almost 50\% believe that students in general learn more in face-to-face classes (Barnes, 2017, pg. 95). Further analysis of the data found demographic differences between students who seemed to prefer face-to-face vs online courses. Older (non-traditional) students were more likely to indicate that more - or equivalent - learning takes place in online courses (Barnes, 2017, pg. 96). In another recent study, the researchers found that students who had previously taken online courses were more likely to believe that they learned as much or more in an online setting as compared to faceto-face classes, and prefer online courses, while students who are new to online learning are more skeptical (Dobbs et al., 2017). Thus, this issue is far from settled and may depend on both student and instructor factors. It is important to recognize that the instructor controls the design of the course and should establish learning outcomes that are the same as those for the face-to-face version of the course. Good course design and clearly articulated learning outcomes will ensure that online students achieve similar levels of learning as those in traditional face-to-face courses.

Another very common perception is that student cheating in online courses is rampant. There are two distinct approaches to addressing this concern. The first is to turn to research on the issue, which has been mixed (GetEducated.com). Although some studies have found that cheating occurs at higher rates in online courses, others have reached the opposite conclusion. Most studies that have examined this issue have found no difference. Since it is difficult to put this question to rest via empirical research, a more promising approach is to build an online course in a way that discourages or prevents cheating. Some online courses require 
students to take exams at a testing center, producing identification and subjecting themselves to observation throughout. Others make use of current technology to "watch" the exam takers through webcams. Several third party providers offer this service to online educators. Finally, the use of authentic assessment makes it very difficult for a student to fake or copy homework. Authentic assessment requires students to submit work that integrates what they have learned with their personal experience, and uses assignments that are unique to the situation and change with each offering of the course and/or each student. Unfortunately, it is impossible to prevent cheating entirely. However, the prevalence of cheating in online courses is likely no different than that in face-to-face courses.

Another myth addressed on the Xavier website is that online courses are most appropriate for subjects that are mostly focused on presenting content, and therefore not appropriate for courses that require discussion and interaction. Online courses can be very engaging and interactive, and can be designed to ensure that all levels of Blooms' taxonomy are addressed. However, this requires careful course design, and instructor engagement with the students during the implementation and administration of the course.

Interestingly, some of the myths associated with online instruction discount the challenge of developing an online course. Two of these misconceptions, both discussed on the Xavier site are that online courses are easier to teach and an online course can be developed by simply uploading the PowerPoint files and quizzes developed for the face-to-face course. Those who hold these views are guilty of confusing convenience with ease. Although the flexibility is a great benefit, the actual time spent teaching is at least as much as for a face-to-face course. In addition, the distribution of the time commitment is different, with a much bigger time commitment in the preparation phase. Since online content delivery must be engaging and interactive, the materials designed for a face-to-face course typically must be modified to make them appropriate for online. Multiple methods of content delivery should be used to maintain student 


\section{BRC Journal of Advances in Education Vol. 3, No. 1}

interest and provide opportunities for feedback. This usually requires adjustments of face-to-face materials and the implementation of learning objects and other tools that are specifically designed to work well in an online environment. While the learning outcomes are the same, the path to achieve them is not necessarily the same as in a face-to-face class. Research on best practices in online teaching provides resources to those who are developing and planning courses (see, for example, Fajardo, 2014 and Strandberg \& Campbell, 2014).

A related misconception is that an online instructor can log in once a week to check the students' work and the course will "run itself." Although much of the planning and content development occurs prior to the launch of the course, a successful online course requires frequent contact, usually daily. Students must feel the instructor's presence throughout the course, through announcements, reminders, posts to discussions and feedback. Research indicates that the instructor's presence can have an important impact on student learning (Bangert, 2008; Richardson et al., 2015). Best practices dictate that online instructors must be prepared to respond to student communications quickly, usually in less than 24 hours. A recent study of instructors' perceptions of instructor presence found that prompt replies to student questions was among the strategies that instructors used to promote their presence (Richardson et al, 2016, pg. 88).

Some instructors believe that online courses do not lend themselves to group work. This is especially off-putting because employers are increasingly demanding teamwork skills. However, students in online courses can use the same technology tools that are used in the work environment to connect employees at multiple locations. This includes web conferencing software and other web-based tools for collaboration. Online courses should not only require individual work, but also create opportunities for students to interact with one another. This helps students to feel less isolated in the online education environment. In addition, instructors should anticipate that students will consult with others as they prepare assignments. Thus, the assignments should be 
authentic and engaging to reduce incentives and opportunity to outsource the work. As discussed previously, this also helps to address the issue of student cheating.

A final misconception discussed on the Xavier site is that online instructors do not get to know their students very well. This might be of particular concern to those who teach at small institutions where they derive great satisfaction from getting to know their students. Best practices include introductory activities that will enable faculty and students to get to know one another just as they do in a face-to-face class. Our own experiences confirm that instructors will get to know some online students quite well through frequent interactions, while others will stay under the radar - just like in a face-to-face class.

\section{The Online MBA: Structure And Support Mechanisms}

The two authors developed and taught two different online accounting courses in a fully-online MBA program that launched in fall 2016.

\section{Preview Complete}

This completes the limited preview of this paper. Please visit the link below to purchase.

\section{Citation Information}

Fischer, Carol M., and Michael J. Fischer. "Online Teaching: Myths, Misconceptions, and Cold Hard Realities.” BRC fournal of Advances in Education 3, no. 1 (2018): 31-46. http://dx.doi.org/10.15239/ j.brcadvje.2018.03.01.ja03 